\title{
Determination of elastic constants of functionalized graphene-based epoxy nanocomposites: A molecular modeling and MD simulation study
}

Aman Yadav ( $\square$ aman49936@gmail.com )

GLA University Institute of Engineering and Technology

Amit Kumar

GLA University Institute of Engineering and Technology

Kamal Sharma

GLA University Institute of Engineering and Technology

\section{Research Article}

Keywords: Mechanical properties, functionalized graphene, Cross-linked epoxy resin, Molecular Dynamics (MD) simulation

Posted Date: August 11th, 2021

DOl: https://doi.org/10.21203/rs.3.rs-693132/v1

License: (c) (i) This work is licensed under a Creative Commons Attribution 4.0 International License. Read Full License 


\title{
Determination of elastic constants of functionalized graphene-based epoxy nanocomposites: A molecular modeling and MD simulation study
}

\author{
Aman Yadav, Amit Kumar, Kamal Sharma \\ Department of Mechanical Engineering, Institute of Engineering \& Technology, GLA \\ University, Mathura 281406, India \\ \# Corresponding author: aman49936@gmail.com
}

\begin{abstract}
The effect of carboxyl $(-\mathrm{COOH})$ functionalized graphene $(\mathrm{FG})$ on the mechanical properties of its epoxy-based nanocomposites has been investigated by Molecular Dynamics (MD) simulations. Simulations cells of nanocomposites with varying wt\% of FG (1, 2 \& $3 \mathrm{wt} \%)$ were constructed using Material Studio 6.0. Obtained MD simulation results show improved mechanical properties such as elastic modulus, bulk modulus, shear modulus, and the Poisson ratio of the FG/epoxy nanocomposites than that of pure epoxy. Moreover, the computational results of nanocomposites have also been validated well with existing experimental data. Therefore, the current MD simulation shows a decent computational sign for the existing experimental and simulation outcomes on mechanical properties of FG/epoxy nanocomposites.
\end{abstract}

Keywords: Mechanical properties; functionalized graphene; Cross-linked epoxy resin; Molecular Dynamics (MD) simulation. 


\section{Introduction}

Graphene is a new two-dimensional (2-D) material, which was discovered in 2004. Due to its excellent mechanical, electrical, and thermal properties concerned wonderful interests from several engineering fields [1]-[4]. In recent times, functionalized graphene and its derivatives are used as a reinforced filler to improve the mechanical properties of polymer nanocomposites followed as potentially durable, tough, and lightweight materials [5]-[7].

Graphene is an allotrope of carbon one atom thick consisting of a single layer of carbon atom arranged in two dimensional (2-D) honeycomb lattice was discovered by Novoselov et al. [8]. In graphene, each atom is associated with its three closest sigma bond and put up one electron to a conduction band that expands above the entire sheet. Graphene is yet the centerpiece of many researchers doing efforts in the field of polymer nanocomposites [9]. Graphene can be manufactured by the exfoliation of graphite as a single layer, double layers, multilayers. The faith is increased in graphene outstanding has greater characteristics that high strength (1.0 TPa) [3] stiffness $(0.7 \mathrm{TPa})$, thermal conductivity $3500 \mathrm{Wm}^{-1} \mathrm{~K}^{-1}$ and surface area $\left(2630 \mathrm{~m}^{2} / \mathrm{g}\right)$ [10], [11], optical transmittance $(97.7 \%)$ [12], electrical conductivity the recent density of $108 \mathrm{~A} / \mathrm{cm}^{2}$ and able to carrying densities of electrical higher than copper [13]. Researchers belong to the field of polymer composites that preferred graphene as a reinforcing element due to its outstanding mechanical and thermal properties [14].

Epoxies are also known as thermosetting polymers consist of 3D cross-linked structures. Epoxies with 3D cross-linked structures show enhanced properties to make the materials more attractive for various applications such as electronic packaging, adhesives, coatings, 
composite materials, etc. Amongst various researchers' characteristics associated with polymers, limited efforts were made to study the cross-linking process and structureproperty association of cross-linked polymers and their composites. In this paper, crosslinked structures are found by the reaction amongst LY556 epoxy resins and HY951 curing agents (hardeners). To accomplish 3D cross-linked structures, one of the reactants from the LY556 resin or HY951 hardener can be multifunctional. The cross-linked polymers have permanent covalent bonds and cannot be re-shaped and re-melted. Various investigators considered the epoxy polymers caused from EPON 862 resin cross-linked with triethylenetetramine (TETA) [15], [16] curing agents, and diethyl toluene diamine (DETDA) [17]-[20]. Cross-linking of DGEBA resin with methylene glycol di-paminobenzoate (TMAB) [21], isophorone diamine (IPD) [22], diamine [23], diamino diphenyl sulfone (DDS) [24], tri DETDA [25], (poly-oxy propylene) (POP) diamines [26] and methylene di-aniline (MDA) [27] were replicated studied by researchers. For instant, Tsige and Stevens [28] examined the effects of cross-linking functionality and interfacial bond density on the crack behavior of extremely cross-linked polymer networks. Hölck et al. [29] calculated the mechanical performance of the nanocomposite obtained by cross-linking amongst phenol novolac epoxy resin and bisphenol-A hardener. They have examined the interfacial properties of cross-linking of epoxy phenol novolac (EPN) and $\mathrm{SiO}_{2}$ layers nanocomposites using MD. Also, various researchers examined the effect of Molecular dynamics (MD) simulations on the performance of cross-linked epoxy nanocomposites reinforced with $\mathrm{SiC}$ [15], $\mathrm{Al}_{2} \mathrm{O}_{3}$ [15] nanoparticles, and carbon nanotubes (CNT) [30], [31]. Further several studies associated with MD simulations and the modeling of cross-linked nanocomposites had been found in the literature [32]-[34]. 
Liang et al. [7] investigated the mechanical properties of graphene oxide (GO)/ poly (vinyl alcohol) (PVA) nanocomposites fabricated using a water solution processing method. They found that Young's modulus and tensile strength of nanocomposites increased by $62 \%$ and $72 \%$, respectively, for low concentrations GO (0.7 wt $\%)$. Likewise, Qi et al. [35] fabricated liquid crystalline epoxy grafted GO infused epoxy composites. Results showed that the reinforcement of $1.5 \mathrm{wt} \%$ of fillers enhance the tensile strength of composites by $48 \%$ (from 55.43 to $80.85 \mathrm{MPa}$ ) compared to pure epoxy.

Now in days, molecular modeling and simulation of materials is an effective method to solve real-world problems at an optimized cost and its offers to explore the research up to a certain extent. Nayebi et al. [36] studied the mechanical properties of graphene/ polythiophene (PT) composites by MD simulations. Computed Young's modulus of graphene/PT composites was $99.6 \mathrm{GPa}$, which is higher than the calculated value of pure PT, i.e. 1.29 GPa, as well as the experimental value of $1.5 \mathrm{GPa}$. In another research, Lee et al. [37] examined the mechanical properties of FG reinforced epoxy nanocomposites based on their interaction energy using MD simulation. Results indicated that graphene functionalized with both $-\mathrm{COOH}$ and $-\mathrm{NH}_{2}$ functional groups improved the tensile strength, modulus, and toughness of nanocomposites. Lin et al. [38] examined that the Young's and shear moduli increased as graphene weight fraction rises and decreased as the temperature rises of graphene/PMMA nanocomposite with the help of MD simulations. Shen et al. [3] examined the mechanical properties of the nanocomposites at room temperature. And, Young's modulus of the epoxy was increased from 2 GPa to 3.1 GPa. Yu [39] examined Young's modulus of AG/epoxy nanocomposites through $\mathrm{C}-\mathrm{N}$ 
covalent bond was improved by $4.563 \mathrm{GPa}$, which is $51 \%$ higher compared with pure epoxy.

This paper examined the effect of $-\mathrm{COOH}-\mathrm{FG}$ on the mechanical properties of $\mathrm{FG}$ reinforced cross-linked epoxy resin nanocomposites. Key investigation parameters such

as $(\mathrm{E}, \mathrm{K}, \mathrm{G}$, and $v)$ have been measured for three different wt\% of -COOH-FG/ epoxy nanocomposites. MD simulation results were compared with the investigational results as well as in good agreement with the experimental work. Also, there is no analogous study on molecular simulation of LY556 epoxy resin cross-linked with DETA curing agent to estimate the mechanical properties of FG/epoxy nanocomposites with different wt $\%$ of graphene using MD simulation methods.

\section{MD simulation section}

\subsection{Simulation Cross-linking Process between the DGEBA and DETA}

Chemical structures of DGEBA and DETA before the cross-linking are of DGEBA LY556 epoxy resin $(\mathrm{C} 18 \mathrm{H} 21 \mathrm{ClO} 3)$ and DETA curing agent $(\mathrm{C} 6 \mathrm{H} 18 \mathrm{~N} 4)$ represents in Figure 1. According to Figure 1(a), DGEBA consists of the bi-functional reactant by two epoxide groups at both ends, whereas Figure 1 (b) shows the DETA consists of five reactive sites with primary as well as secondary amine groups and hence is a multifunctional (fivefold-functional) reactant. Due to this, each DETA molecule can be reacted with five DGEBA molecules also capable to associate with another DETA molecule by its second epoxide head. Hence, DGEBA and DETA can produce 3D crosslinked epoxy polymers. 
(a)

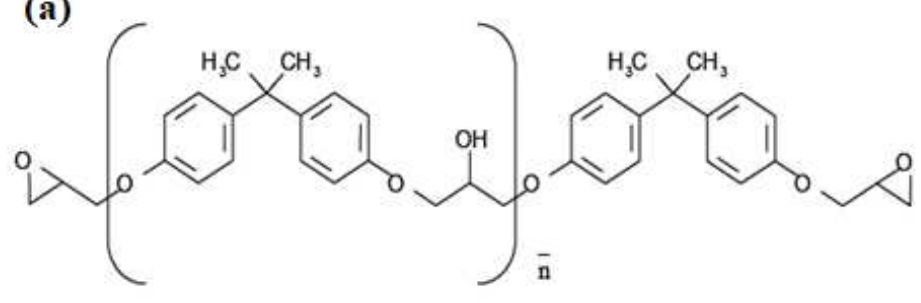

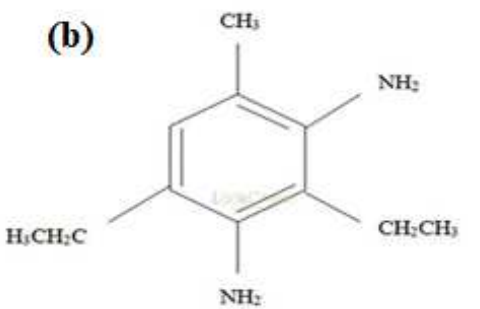

Figure 1. Molecular structures (a) LY556 epoxy resin (b) DETA before cross linking.

In LY556 epoxy resin, the $\mathrm{C}-\mathrm{O}$ bond of each epoxide group is improved to form a reactive $-\mathrm{CH}_{2}$ site represent in Figure 2, thus it can be cross-linked with a curing agent. Molecules of LY556 epoxy resin contain two epoxide groups at both ends which react with the hydrogen atoms present in amine groups of the HY951 curing agent. Additionally, the resulting resin molecule is again associated with the epoxy molecules at the site of $\mathrm{HN}$ and $\mathrm{NH}_{2}$ groups' also one HY951 molecule is associated with another epoxide group. In conclusion, crosslinking between the LY556 epoxy resin and the HY951curing agent has been established. The LY556 epoxy resin and HY951 curing agent molecules generate more crosslinks by keeping the reaction continuous. The motion of crosslinking's are in all directions and produced a network of macromolecules [40], [41].

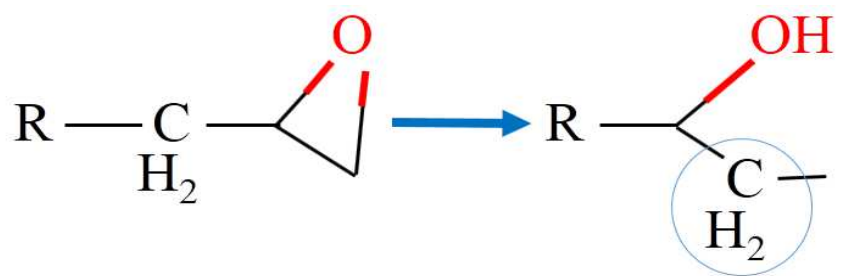

Figure 2. Conversion of epoxide group to a reactive one through breaking the $\mathrm{C}-\mathrm{O}$ bond.

\subsection{Molecular modeling of cross-linked epoxy resin and carboxyl (-COOH) functionalized graphene}


LY556 epoxy resin is used as a thermoset polymer matrix which has many epoxide groups for each molecule displays outstanding high elastic modulus, thermal conductivity, and corrosion resistance. Due to these exceptional properties, LY556 epoxy resin as a polymer matrix was used to construct polymer nanocomposites in different engineering areas. Figure 3(a) represented the molecular model of LY556. Hydrogen atoms present in the amine $\left(-\mathrm{NH}_{2}\right)$ groups of the curing agent (di-ethylene toluene diamine -DETDA) react with the epoxide groups of epoxy resin molecules (Figure 3 (b)). Further, result cured resin molecules (Figure 3 (c)) react with the epoxy molecule at the site of $\mathrm{HN}$ and $\mathrm{NH}_{2}$ and one curing agent molecule reacts at the site of another epoxide group. Hence, the cross-linking was established between the curing agent and epoxy resin represents in Figure 3(d). Finally, the effect remains, produces more cross-links motions in all directions between the curing agent and epoxy resin [41], [42]. All the constructed cells were relaxed through energy minimization processes using MD simulations package Material Studio 6.0. Graphene was functionalized with carboxyl groups, which are randomly attached to the carbon atoms of graphene sheet, as shown in Figure 4 (b). 


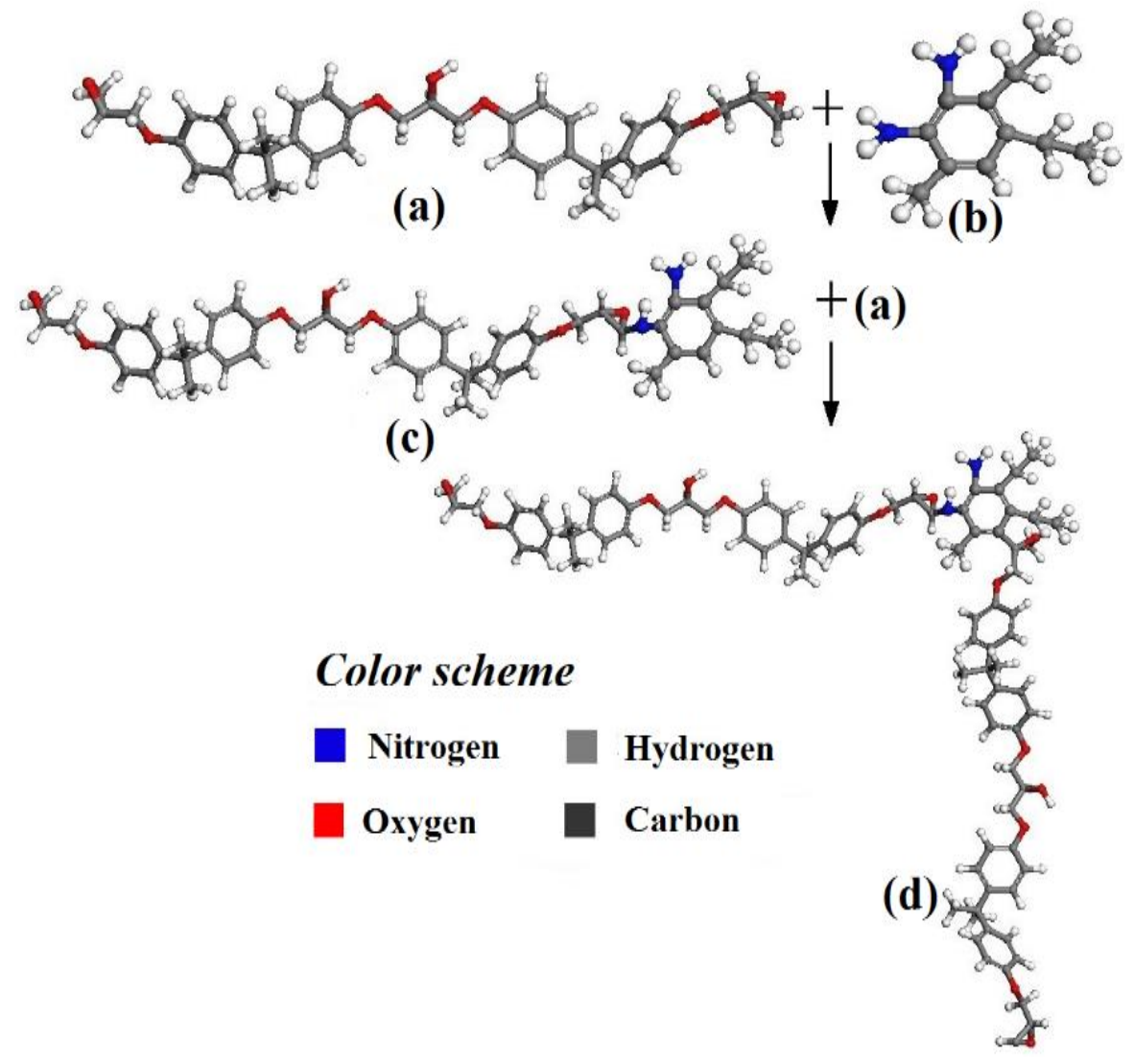

Figure 3. Molecular structure of (a) LY556 epoxy resin (b) curing agent (TETA) (c) cured epoxy resin and (d) cross-linked LY556 epoxy resin.

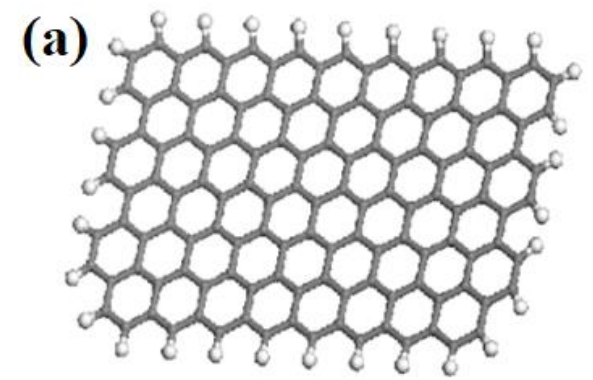

Pristine graphene

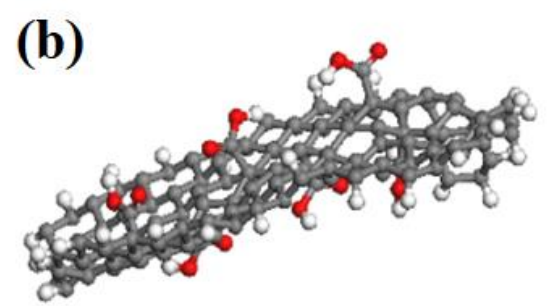

$\underset{\text { graphene }}{-\mathrm{COOH} \text { functionalized }}$

Figure 4. Molecular model of pristine graphene (a), and $-\mathrm{COOH}$ functionalized graphene (b). 


\subsection{Simulation models}

In the present work mechanical properties of FG/epoxy nanocomposites are predicted by MD simulations. After, equilibration process a model of FG/epoxy nanocomposite is represented in Figure 5, containing an amorphous cell-sized 4.48×4.48×4.48 nm3, with a low density of $0.5 \mathrm{~g} / \mathrm{cc}$ has been created at room temperature under the periodic boundary conditions. Energy minimization of MD simulations has been done to achieve the stable structure of a model, subsequently, the potential, lattice parameters, and non-bond energy are set. Later, step by step process of MD simulation has been completed with a time of 1 fs and $1 \mathrm{~atm}$ at $298 \mathrm{~K}$, to obtain a real density and balance the system. After minimization, the system has been subjected to $270 \mathrm{ps}$ at $298 \mathrm{~K}$ and $1 \mathrm{~atm}$, to provide suitable kinetic energy to attain degrees of cross-linking, and a cut-off value of $5 \AA$ has been adopted in our scheme to avoid highly strained structures and increased the chance of curing sites to fall within the reaction cut-off distance. Hence, new covalent bonds are formed and the cross-linking density is calculated. The above steps are replicate till no new covalent bonds are formed by the assumed cut-off distance $(5 \AA)$. At last, the final cross-linked models are slowly cooled at room temperature to get the elastic moduli we functional a strain of 0.005 , and the thickness of the graphene sheet is assumed to be 3.4 $\AA$.

In this paper, the epoxy resin as LY556 (DGEBA) cross-linked with a curing agent as (DETDA) has been used as a polymer matrix. A single-layer graphene sheet with 164 carbon atoms was selected as a nanofiller in the nanocomposites. Chemical functionalization has been carried out to obtain a strong adhesive interface and good dispersion amongst the graphene and polymer chain. Many problems occur when 
graphene was used as a reinforcing nanofiller in epoxy nanocomposites. To overcome these problems of dispersion as well as an agglomeration of graphene in polymer composites, a chemical covalent bond technique was used to maintain the stable bonds between FG and epoxy chains. Figure 6 represents the polymer structure of LY556 epoxy resin cross-linked with a curing agent (DETDA) containing 99 epoxy chains. Figures 7 (a-c) show the simulation cells of epoxy nanocomposites reinforced by three different wt $\%$ of $-\mathrm{COOH}-\mathrm{FG}$.
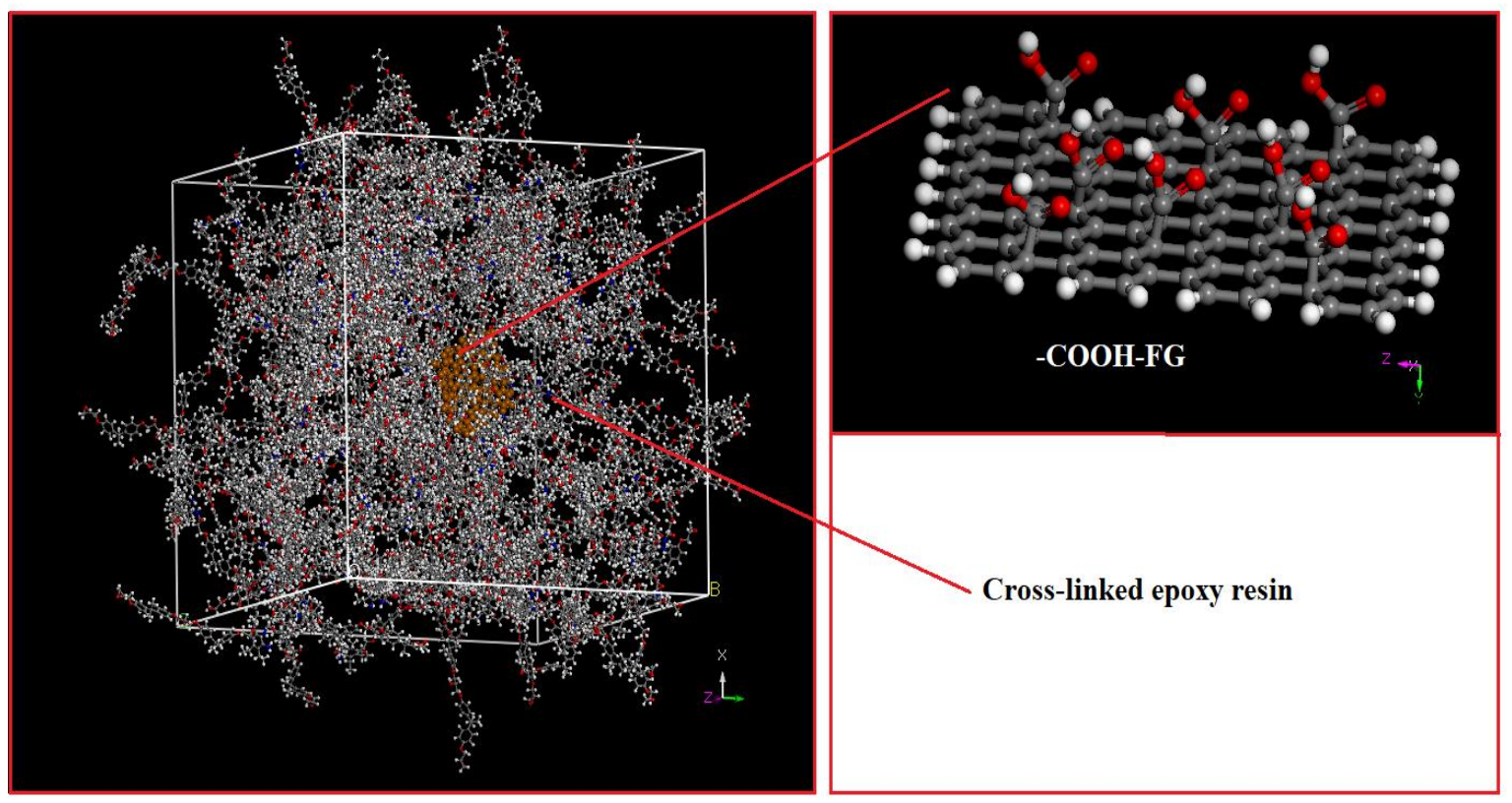

Figure 5: Molecular model of nanocomposite consists of cross-linked LY556 epoxy resin with $-\mathrm{COOH}-\mathrm{FG}$ as filler. 


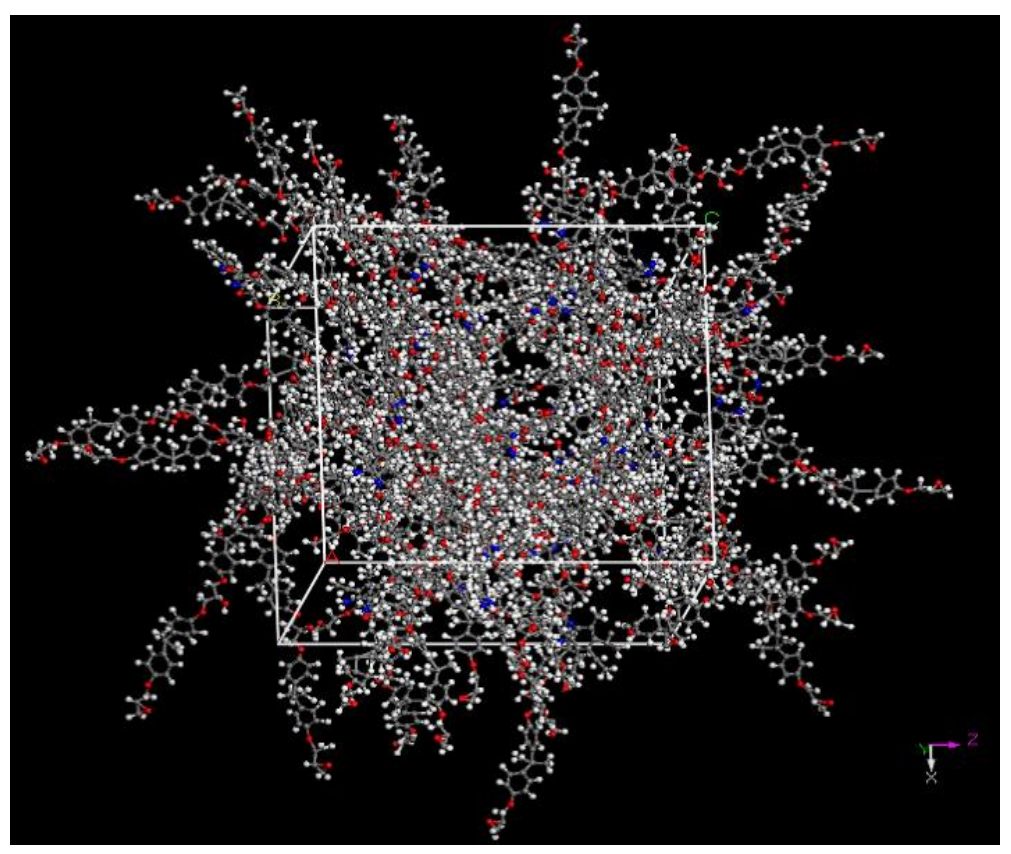

Figure 6. Molecular model of LY556 epoxy resin as a matrix.

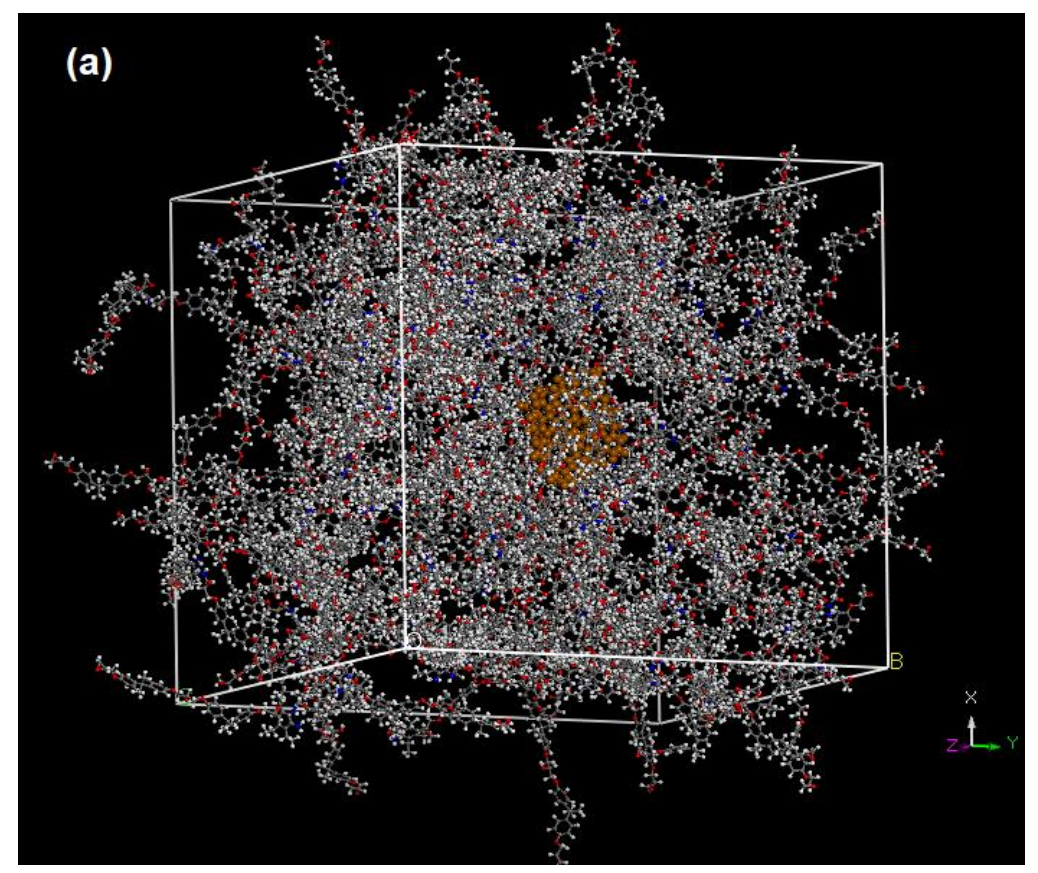



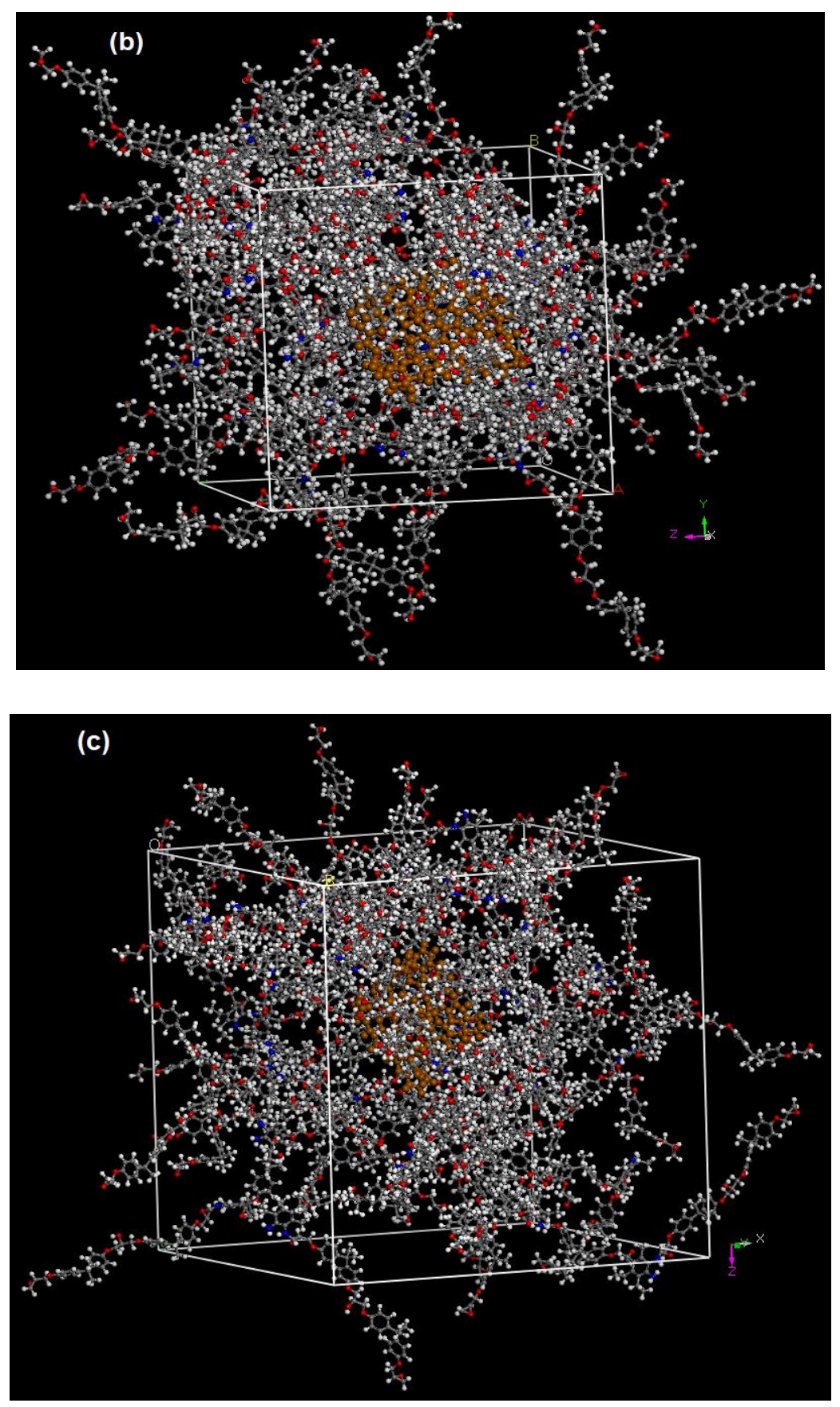

Figure 7. Molecular model of nanocomposites consists of -COOH-FG/ LY556 epoxy resin (a) $1 \mathrm{wt} \%$ (b) $2 \mathrm{wt} \%$ (c) $3 \mathrm{wt} \%$.

\subsection{Forcefield and simulation method}

Polymer consistent force-field (Pcff30) forcefield was used throughout this research. Pcff30 is the newest MD simulation technique used to adjust the Pcff computational 
model. Pcff30 has been used in the entire dynamic direction and many molecules as an $a b$ initio force-field. $A b$ initio forcefield is used to determine the properties of many molecules like polymers, most repeated organics, and minor inorganic molecules [43], [44]. Pcff30 forcefield contains three different classes of energy terms as cross-terms, the bonded energy terms, and nonbonded energy terms. Covalent bond stretching, torsion angle rotation energy, bond angle bending of the polymer chain represents the bonded energy terms. While, cross-terms and nonbonded energy terms are made of Coulombic electrostatic and the van der Waals force, correspondingly here the use of Lennard-Jones potential equation to obtained van der Wall interaction and the various functional forms in Pcff30 force field has been discussed by H. Sun [45], and are as follows in Eq. 1:

$\mathrm{E}_{\text {total }}=\mathrm{E}_{\mathrm{valence}}+\mathrm{E}_{\text {cross-term }}+\mathrm{E}_{\text {non-bond }}$

The valence energy term consisted of the covalent bond-stretching energy, Ebond; the bond-angle bending energy, $\mathrm{E}_{\text {angle; }}$, the torsion-angle rotation energy of the polymer chain, $\mathrm{E}_{\text {torsion; }}$; and the out-of-plane energy, $\mathrm{E}_{\mathrm{oop}}$, as discussed in Eq. 2.

$$
\begin{gathered}
\mathrm{E}_{\text {valence }}=\mathrm{E}_{\text {bond }}+\mathrm{E}_{\text {angle }}+\mathrm{E}_{\text {torsion }}+\mathrm{E}_{\mathrm{oop}} \\
E_{\text {valence }}=\sum_{b}\left[K_{2}\left(b-b_{0}\right)^{2}+K_{3}\left(b-b_{0}\right)^{3}+K_{4}\left(b-b_{0}\right)^{4}\right] \\
+\sum_{b}\left[H_{2}\left(\theta-\theta_{0}\right)^{2}+H_{3}\left(\theta-\theta_{0}\right)^{3}+H_{4}\left(\theta-\theta_{0}\right)^{4}\right] \\
+\sum_{\varnothing}\left\{V_{1}\left[1-\cos \left(\emptyset-\emptyset_{1}^{0}\right)\right]+V_{2}\left[1-\cos \left(2 \varnothing-\emptyset_{2}^{0}\right)\right]+V_{3}\left[1-\cos \left(3 \emptyset-\emptyset_{3}^{0}\right)\right]\right\} \\
+\sum_{x} K_{x} x^{2}
\end{gathered}
$$


The terms for cross-interactions included the dynamic variations among the bond stretching interactions between two bonds, $\mathrm{E}_{\text {bond-bond; }}$ bond-bond interactions between two valence angles associated with a common vertex atom, $E_{\text {angle-angle; }}$ stretch bond interactions, between a two-bond angle and one of its bonds, Ebond-angle; stretch-torsion interactions between a dihedral angle and one its middle bond, Emiddle-bond-torsion; stretchtorsion interactions between a dihedral angle and one of its end bonds, $\mathrm{E}_{\text {end-bond-torsion; }}$ bend torsion interactions between a dihedral angle and one of its valence angles, $\mathrm{E}_{\text {angle-torsion; }}$; bend torsion interactions between a dihedral angle and its two valence angles, Eangle-angle-torsion, as discussed in Eq. 3.

$$
\begin{aligned}
& \mathrm{E}_{\text {cross-term }}=\mathrm{E}_{\text {bond-bond }}+\mathrm{E}_{\text {angle-angle }}+\mathrm{E}_{\text {bond-angle }}+\mathrm{E}_{\text {middle-bond-torsion }}+\mathrm{E}_{\text {end-bond-torsion }}+ \\
& \mathrm{E}_{\text {angle-torsion }}+\mathrm{E}_{\text {angle-angle-torsion }} \\
& E_{\text {cross-term }}=\sum_{b} \sum_{b^{\prime}} F_{b b^{\prime}}\left(b-b_{0}\right)\left(b^{\prime}-b_{0}^{\prime}\right) \\
& +\sum_{\theta} \sum_{\theta^{\prime}} F_{\theta \theta^{\prime}}\left(\theta-\theta_{0}\right)\left(\theta^{\prime}-\theta_{0}^{\prime}\right) \\
& +\sum_{b} \sum_{\theta} F_{b \theta}\left(b-b_{0}\right)\left(\theta-\theta_{0}\right) \\
& +\sum_{b} \sum_{\varnothing} F_{b \phi}\left(b-b_{0}\right)\left[F_{1} \cos \emptyset+F_{2} \cos 2 \emptyset+F_{3} \cos 3 \emptyset\right] \\
& +\sum_{b^{\prime}} \sum_{\emptyset} F_{b^{\prime} \phi}\left(b^{\prime}-b_{0}^{\prime}\right)\left[V_{1} \cos \emptyset+V_{2} \cos 2 \varnothing+V_{3} \cos 3 \varnothing\right] \\
& +\sum_{\theta} \sum_{\varnothing} F_{\theta \phi}\left(\theta-\theta_{0}\right)\left[V_{1} \cos \emptyset+V_{2} \cos 2 \varnothing+V_{3} \cos 3 \varnothing\right] \\
& +\sum_{\varnothing} \sum_{\theta} \sum_{\theta^{\prime}} K_{\varnothing \theta \theta^{\prime}} \cos \emptyset\left(\theta-\theta_{0}\right)\left(\theta^{\prime}-\theta_{0}^{\prime}\right)
\end{aligned}
$$


The non-bond energy terms represent the Coulomb electrostatic force, $\mathrm{E}_{\mathrm{Columb}}$; and the vdW force, $E_{\mathrm{vdW}}$, as discussed in Eq. 4-5.

$$
\begin{aligned}
\mathrm{E}_{\text {non-bond }} & =\mathrm{E}_{\mathrm{Columb}}+\mathrm{E}_{\mathrm{vdW}} \\
E_{\text {non-bonded }} & =\sum_{i>j} \frac{q_{i} q_{j}}{\varepsilon r_{i j}}+\sum_{i>j}\left[\left(\frac{A_{i j}}{r_{i j}^{9}}\right)-\left(\frac{B_{i j}}{r_{i j}^{6}}\right)\right]
\end{aligned}
$$

where $\mathrm{q}$ is the atomic charge, $\varepsilon$ is the dielectric constant and $\mathrm{r}_{\mathrm{ij}}$ is the distance between atom pairs.

' $b$ ' is the internal coordinates of the bond, ' $b$ ' is the length of the other $\mathrm{O}-\mathrm{H}$ bond, ' $\theta$ ' is the bond angle, ' $\varphi$ ' is the torsion angle obtained by twisting the atoms about the bond axis, $x$ is the out of plane angle, $K_{i}(i=2-4), b_{0}, H(\mathrm{i}=2-4)_{i}, \theta_{0,} V_{i}(=1-3), \theta_{0}^{\prime}, \emptyset_{i}^{0}(=1-3), F_{b b^{\prime}}, F_{\theta \theta^{\prime}}, F_{b \theta}, F_{b \phi}$, $F_{b^{\prime} \phi}, F_{\theta \phi}, K_{\varnothing \theta \theta^{\prime}}, A_{i j}, B_{i j}$ are fitted from quantum mechanics calculations and are implemented into the Discover module of Materials Studio.

Firstly, geometry optimization was done at the maximal displacement of $0.005 \AA$, atomic force $0.05 \mathrm{eV}$, the total energy $1 \times 10^{-6} \mathrm{eV} /$ atom, stress $0.005 \mathrm{GPa}$, and cut-off energy $270.0 \mathrm{eV}$. Furthermore, the amorphous cell was constructed at room temperature with the help of a module tool and parameters such as an initial density of $0.5 \mathrm{~g} / \mathrm{cc}$. Here, the COOH-FG with wt $\%$ of 1,2 , and $3 \%$ and the number of loading is 1 consist LY556 epoxy resin with wt $\%(99,98,97 \%)$ and the number of loading are $111,55,37$. In all simulations, the atom is constructed with the help of MD simulation method to examine the elastic properties of nanocomposites by assuming the cut-off distance ( $5 \AA$ ). Medium- 
range alterations are also functionalized on the cut-off distance to remove the nonbonded interactions hence, avoids the breaks produced by direct cut-offs.

\subsection{Methodology to calculate mechanical properties}

There are three main methods to evaluate the mechanical properties of nanocomposites by MD simulations, fluctuation formula [46], dynamics (constant-stress molecular dynamics), and static (constant-strain minimization) [47]. In the present work, the static method was used to calculate the mechanical properties of - COOH-FG based crosslinked epoxy systems. Stress-strain behavior for linear elastic materials can be described by Hooke's law (Eq. 6):

$$
\sigma_{i}=C_{i j} \varepsilon_{j}
$$

Where, $\mathrm{i}, \mathrm{j}=1,2,3 . \sigma_{i}$ and $\varepsilon_{j}$ are the 6-dimensional stress-strain vectors, and $C_{i j}$ is the $6 \times 6$ stiffness matrix. The strain amplitude was set to 0.005 to obtain the elastic constants. The stress components were calculated using the so-called viral expression (Eq. 7) [48].

$$
\sigma_{i j}=-\frac{1}{V} \sum_{k}\left[m^{k}\left(u_{i}^{k} u_{j}^{k}\right)+\frac{1}{2} \sum_{i \neq j}\left(r_{i}^{k l}\right) f_{j}^{l k}\right]
$$

Where $\mathrm{V}$ is the volume, $\mathrm{m}^{\mathrm{k}}$ and $\mathrm{u}^{\mathrm{k}}$ stand for the mass and velocity of the $\mathrm{k}^{\text {th }}$ particle, respectively, $\mathrm{r}^{\mathrm{kl}}$ is the distance between $\mathrm{k}^{\mathrm{th}}$ and $\mathrm{l}^{\mathrm{th}}$ particles, and $\mathrm{f}^{\mathrm{k}}$ represents the force exerted on $\mathrm{l}^{\text {th }}$ particle by $\mathrm{k}^{\text {th }}$ particle.

The Lamé coefficients, $\lambda$ and $\mu$, can be calculated using any two of the following equations (8-13).

$$
\begin{gathered}
\lambda=\frac{1}{6}\left(C_{12}+C_{13}+C_{21}+C_{23}+C_{31}+C_{32}\right) \approx \frac{1}{3}\left(C_{12}+C_{23}+C_{13}\right) \\
\mu=\frac{1}{3}\left(C_{44}+C_{55}+C_{66}\right)
\end{gathered}
$$




$$
\begin{gathered}
\lambda+2 \mu=\frac{1}{3}\left(C_{11}+C_{22}+C_{33}\right) \\
E=\frac{\mu(3 \lambda+2 \mu)}{\lambda+\mu} \\
K=\lambda+\frac{2}{3} \mu \\
G=\mu
\end{gathered}
$$

Where, K, E, and G are bulk, Young's, and shear moduli, respectively.

\section{Results and discussion}

The calculated mechanical properties of FG/LY556 cross-linked epoxy nanocomposites with graphene wt $\%(1,2,3 \mathrm{wt} \%)$ as illustrated in Table 5. Table 1 represents the elastic stiffness matrix of LY556 cross-linked epoxy which is obtained by the Forcite calculation available in the module tool of Material Studio software to calculate its mechanical properties. - COOH-FG acts as nano reinforcement while LY556 cross-linked epoxy resin act as a matrix in the nanocomposite's unit cell. Similarly, tables $2,3 \& 4$ elucidate the elastic stiffness matrix of nanocomposites for 1,2 , and $3 \mathrm{wt} \%$ of -COOH-FG, respectively.

Table 1. Elastic stiffness matrix of LY556 cross-linked epoxy resin

\begin{tabular}{|c|c|c|c|c|c|c|}
\hline $\mathrm{C}_{\text {ii }}$ & 1 & 2 & 3 & 4 & 5 & 6 \\
\hline 1 & 2.8591 & 31173 & 1.7135 & 0.4975 & 1.4771 & 1.6744 \\
\hline 2 & 3.1173 & 11.3661 & -2.0953 & 1.0571 & 0.4121 & -2.6205 \\
\hline 3 & 1.7135 & -2.0953 & -1.5148 & -0.3648 & -0.1665 & 0.9557 \\
\hline 4 & 0.4975 & 1.0571 & -0.3648 & 0.6777 & 0.2761 & 0.2752 \\
\hline 5 & 1.4771 & 0.4121 & -0.1665 & 0.2761 & 0.5612 & -1.7748 \\
\hline
\end{tabular}




\begin{tabular}{|l|l|l|l|l|l|l|}
\hline 6 & 1.6744 & -2.6205 & 0.9557 & 0.2752 & -1.7748 & 4.0594 \\
\hline
\end{tabular}

Table 2. Elastic stiffness matrix of $1 \mathrm{wt} \%$-COOH-FG reinforced nanocomposites

\begin{tabular}{|c|c|c|c|c|c|c|}
\hline $\mathrm{C}_{\text {ij }}$ & 1 & 2 & 3 & 4 & 5 & 6 \\
\hline 1 & 24.1300 & 9.2676 & 8.4630 & -4.4538 & 3.4157 & -1.1150 \\
\hline 2 & 9.2676 & 22.9101 & 2.6848 & 0.9472 & -0.0022 & -1.3869 \\
\hline 3 & 8.4630 & 2.6848 & 18.3195 & 0.7686 & 3.8437 & -2.5435 \\
\hline 4 & -4.4538 & 0.9472 & 0.7686 & 13.8569 & 1.4798 & -0.3663 \\
\hline 5 & 3.4157 & -0.0022 & 3.8437 & 1.4798 & 7.3565 & -1.0363 \\
\hline 6 & -1.1150 & -1.3869 & -2.5437 & -0.3663 & -1.0363 & 9.45669 \\
\hline
\end{tabular}

Table 3. Elastic stiffness matrix of $2 \mathrm{wt} \%$-COOH-FG reinforced nanocomposites

\begin{tabular}{|c|c|c|c|c|c|c|}
\hline $\mathrm{C}_{\text {ij }}$ & 1 & 2 & 3 & 4 & 5 & 6 \\
\hline 1 & 31.2087 & 12.6570 & 12.8638 & 0.0776 & -0.0847 & -1.0409 \\
\hline 2 & 12.6570 & 28.5437 & 9.5530 & 0.5156 & -2.0786 & 2.0324 \\
\hline 3 & 12.8638 & 9.5530 & 34.5381 & -4.3773 & -1.5950 & -0.7354 \\
\hline 4 & 0.0776 & 0.5156 & -4.3773 & 7.5284 & 1.5574 & -2.4535 \\
\hline 5 & -0.0847 & -2.0786 & -1.5950 & 1.5574 & 8.7474 & 2.5715 \\
\hline 6 & -1.0409 & 2.0324 & -0.7354 & -2.4535 & 2.5715 & 10.6710 \\
\hline
\end{tabular}

Table 4. Elastic stiffness matrix of $3 \mathrm{wt} \%$-COOH-FG reinforced nanocomposites

\begin{tabular}{|c|c|c|c|c|c|c|}
\hline $\mathrm{C}_{\text {ij }}$ & 1 & 2 & 3 & 4 & 5 & 6 \\
\hline 1 & 24.9376 & 0.5042 & 8.6270 & -1.2550 & -0.9807 & 1.7105 \\
\hline 2 & 0.5042 & 25.1693 & 7.4412 & -1.1087 & -1.4330 & 0.0528 \\
\hline 3 & 8.6270 & 7.4412 & 33.5204 & -0.2203 & -0.3764 & -3.9620 \\
\hline 4 & -1.2550 & -1.1087 & -0.2203 & 12.9265 & -1.4070 & -1.2227 \\
\hline 5 & -0.9807 & -1.4330 & -0.3764 & -1.4070 & 7.4964 & -2.8382 \\
\hline 6 & 1.7105 & 0.0528 & -3.9620 & -1.2227 & -2.8382 & 14.2738 \\
\hline
\end{tabular}


As the wt $\%$ of the FG increases from 1 to 2,2 to $3 \%$, at a constant volume, then LY 556 epoxy system is increased with the functionalized graphene molecules increases. Also, simulation results prove that the functionalized graphene-containing LY 556 epoxy resin system shows enhance mechanical properties compared to the pure epoxy resin system. Though, the enhancements are going with the variations. The results illustrate that the functionalized graphene-containing LY 556 epoxy resin system with a 3\% weight fraction has advanced elastic moduli compared with the others. This result is defined by a fact that additional functionalization in functionalized graphene LY 556 epoxy remains as combined particles. The results have a good arrangement with the experimental accomplishment by Lee et al. [37] estimated the improved mechanical properties of epoxy nanocomposites infused with graphene containing both $-\mathrm{NH}_{2}$ and $-\mathrm{COOH}$ functional groups. MD result indicated that the tensile modulus of above-mentioned nanocomposites increases from $3.1 \mathrm{GPa}$ to $3.45 \mathrm{GPa}$ as compared to - $\mathrm{COOH}-\mathrm{FG}$ reinforced nanocomposites. Sun et al. [49] noticed that Young's modulus of graphene/epoxy nanocomposites increases by $2.74 \mathrm{GPa}$ with filler wt\% of 0.88 . Likewise, Rafiee et al. [50] examined the enhancement of elastic modulus is increased by increasing the functional groups with the help of the experiment and various results represented in Table 5.

Approximately, all the examined results for mechanical properties, such as Young's modulus, bulk modulus, the shear modulus is higher than the experimental results as well as compared to simulation results because the simulation systems have no imperfections and is an ideal situation whereas numerous types of imperfections are present in physical models that result in the compact calculated properties. As represents in Table 5, the 
examined value of the elastic modulus is higher than the experimental value. Hence, by increasing the number of atoms in the cell, improved material properties are found.

Table 5. Mechanical properties of $-\mathrm{COOH}-\mathrm{FG} /$ epoxy nanocomposites at room temperature

\begin{tabular}{|c|c|c|c|c|c|c|c|c|}
\hline \multirow[t]{2}{*}{ Materials } & \multirow{2}{*}{$\begin{array}{c}\mathrm{wt} \% \\
\text { of } \\
\text { fillers }\end{array}$} & \multirow{2}{*}{$\begin{array}{c}\text { Young's } \\
\text { modulus } \\
\text { of pure } \\
\text { epoxy } \\
\text { (GPa) }\end{array}$} & \multicolumn{4}{|c|}{ Nanocomposites } & \multirow{2}{*}{$\begin{array}{l}\text { Method } \\
\text { Adopted }\end{array}$} & \multirow[t]{2}{*}{ Ref. } \\
\hline & & & $\begin{array}{c}\text { Young's } \\
\text { modulus } \\
(\text { GPa })\end{array}$ & $\begin{array}{c}\text { Bulk } \\
\text { modulus } \\
(\text { GPa })\end{array}$ & $\begin{array}{c}\text { Shear } \\
\text { modulus } \\
\text { GPa) }\end{array}$ & $\begin{array}{c}\text { Poisson } \\
\text { ratio }\end{array}$ & & \\
\hline Gr-COOH & \multirow{3}{*}{1} & \multirow{3}{*}{3.24} & 3.55 & - & - & - & \multirow{3}{*}{ Experiment } & \multirow{3}{*}{ [37] } \\
\hline $\begin{array}{l}-\mathrm{COOH}+-\mathrm{NH}_{2} \\
\text { Graphene }\end{array}$ & & & 3.66 & - & - & - & & \\
\hline $\mathrm{Gr}-\mathrm{COOH}$ & & & 3.60 & - & - & - & & \\
\hline $\mathrm{Gr}-\mathrm{COOH}$ & 1.2 & - & 4.55 & - & - & - & MD & [39] \\
\hline $\begin{array}{l}\mathrm{COOH} \\
\text { Graphene }\end{array}$ & 0.88 & 2.74 & 4.68 & - & - & - & MD & [49] \\
\hline GS-sPMMA & - & 3.8 & 4.7 & 0.36 & 1.4 & 0.36 & \multirow[t]{2}{*}{ MD } & \multirow[t]{2}{*}{ [51] } \\
\hline FGS-sPMMA & - & 6.0 & 5.0 & 0.31 & 2.3 & 0.31 & & \\
\hline f-GNPs & 1.5 & - & 6.80 & - & - & - & Experiment & [52] \\
\hline$-\mathrm{NH}_{2}$ graphene & 1 & - & 3.1 & - & - & - & Experiment & [53] \\
\hline $\begin{array}{l}\text { Intercalated } \\
\text { graphene }\end{array}$ & \multirow[t]{3}{*}{1} & 3.24 & 5.63 & - & - & - & \multirow[t]{3}{*}{ MD } & \multirow[t]{3}{*}{ [54] } \\
\hline Intercalated GO & & 3.16 & 6.36 & - & - & - & & \\
\hline Graphene flakes & & 3.16 & 5.48 & - & - & - & & \\
\hline GO/f-GO & 0.1 & - & 3.6 & - & - & - & Experiment & [55] \\
\hline GNPs & 1 & - & 2.8 & - & - & - & MD & {$[56]$} \\
\hline Sulfonic GO & 1 & - & 2.36 & - & - & - & Experiment & [57] \\
\hline GO & 1 & 1.66 & 2.25 & 5 & 11 & - & MD & [58] \\
\hline Diazonium-FG & 0.8 & - & 3.20 & - & - & - & Experiment & [59] \\
\hline GO & 0.5 & - & 1.70 & - & - & - & Experiment & [60] \\
\hline FGO & 1 & - & 2.89 & - & - & - & Experiment & [61] \\
\hline Gr-COOH & 1 & - & 9.3 & - & 4 & 0.5 & & \\
\hline$-\mathrm{COOH}+-\mathrm{NH}_{2}$ & 1 & - & 9.4 & - & - & - & MD & [62] \\
\hline
\end{tabular}




\begin{tabular}{|c|c|c|c|c|c|c|c|c|}
\hline Graphene & & & & & & & & \\
\hline GO & 2 & - & 4.45 & - & - & - & Experiment & {$[63]$} \\
\hline$-\mathrm{NH}_{2}-\mathrm{f}-\mathrm{Gr}$ & 1 & - & 3.55 & - & - & - & Experiment & [64] \\
\hline $\begin{array}{l}-\mathrm{COOH} \\
\text { Graphene }\end{array}$ & 0.1 & 2.85 & 3.74 & - & - & - & Experiment & [65] \\
\hline Pure epoxy & - & - & 4.04 & 1.8823 & 1.7661 & 0.04 & \multirow{4}{*}{ MD } & \multirow{4}{*}{$\begin{array}{l}\text { Pres } \\
\text { ent } \\
\text { work }\end{array}$} \\
\hline \multirow{3}{*}{$\begin{array}{c}\text {-COOH-FG/ } \\
\text { epoxy } \\
\text { nanocomposites }\end{array}$} & 1 & - & 9.53 & 8.15 & 10.23 & 0.05 & & \\
\hline & 2 & - & 23.35 & 19.45 & 8.98 & 0.60 & & \\
\hline & 3 & - & 26.49 & 12.45 & 11.56 & 0.15 & & \\
\hline
\end{tabular}

\section{Conclusions}

Molecular modeling of - $\mathrm{COOH}-\mathrm{FG}$ /epoxy nanocomposites has developed to determine the elastic constants such as Young's modulus, bulk modulus, shear modulus, and Poisson ratio. In this study, the MD simulation approach with Pcff30 force-field has been effectively applied to simulate the cross-linked DGEBA (LY556 epoxy resin) with DETA curing agent, nanocomposites with different wt\% of FG. The constant strain approach has been used to calculate the mechanical properties of nanocomposites. The MD results showed that the mechanical properties of nanocomposites significantly improve by adding - $\mathrm{COOH}-\mathrm{FG}$ to cross-linked epoxy. The best results were obtained at $3.0 \mathrm{wt} \%$ of FG, which was in good agreement with experimental as well as related MD simulation work. The MD simulation showed more interaction energy amongst the graphene and surrounding matrix for higher wt $\%$ of graphene and $-\mathrm{COOH}$ functional groups. Therefore, $-\mathrm{COOH}-\mathrm{FG}$ is used as a filler material to improve the elastic constants of the FG/epoxy nanocomposites. Comparing the simulation results with experimental and MD simulation data recognized that the current MD simulation shows a decent 
computational sign for the existing experimental and simulation outcomes on mechanical properties of FG/epoxy nanocomposites.

\section{Funding}

No financial support for the research, authorship, and/or publication of this article.

\section{Conflict of interest}

The authors declare no conflict of interest.

\section{Availability of data and material: NA}

\section{Code availability: NA}

\section{Authors' contributions}

Aman Yadav: Conceptualization, Modelling and simulation, Methodology, Formal analysis, Investigation, Visualization, Writing - original draft, Writing - review \& editing, Amit Kumar: Supervision, Writing - review \& editing. Kamal Sharma: Writing - review \& editing...

\section{References}

[1] K. Novoselov et al., "Electric Field Effect in Electrically Thin Carbon Films," Science (80-. )., 2004.

[2] A. Geim and K. S. Novoselov, "The Rise of Graphene," Nat. Mater., vol. 6, pp. 183-191, Apr. 2007, doi: 10.1038/nmat1849.

[3] C. Lee, X. Wei, J. W. Kysar, and J. Hone, "Measurement of the elastic properties and intrinsic strength of monolayer graphene," Science (80-. )., 2008, doi: 10.1126/science.1157996.

[4] A. A. Balandin et al., "Superior thermal conductivity of single-layer graphene," Nano Lett., 2008, doi: 10.1021/n10731872. 
[5] R. Thillaiyan et al., "Functionalized graphene sheets for polymer nanocomposites," Nat. Nanotechnol., vol. 3, pp. 327-331, Jun. 2008, doi: 10.1038/nnano.2008.96.

[6] Y. Qin et al., "Lightweight, Superelastic, and Mechanically Flexible Graphene/Polyimide Nanocomposite Foam for Strain Sensor Application,” ACS Nano, vol. 9, no. 9, pp. 8933-8941, Sep. 2015, doi: 10.1021/acsnano.5b02781.

[7] J. Liang et al., "Molecular-level dispersion of graphene into poly(vinyl alcohol) and effective reinforcement of their nanocomposites," Adv. Funct. Mater., 2009, doi: 10.1002/adfm.200801776.

[8] K. S. Novoselov et al., "Electric field in atomically thin carbon films," Science (80-. )., 2004, doi: 10.1126/science.1102896.

[9] A. Kumar, K. Sharma, and A. Dixit, "A review on the mechanical and thermal properties of graphene and graphene-based polymer nanocomposites: understanding of modelling and MD simulation," Mol. Simul., vol. 46, pp. 136154, Oct. 2019, doi: 10.1080/08927022.2019.1680844.

[10] A. T. Smith, A. M. LaChance, S. Zeng, B. Liu, and L. Sun, "Synthesis, properties, and applications of graphene oxide/reduced graphene oxide and their nanocomposites," Nano Mater. Sci., vol. 1, no. 1, pp. 31-47, 2019, doi: https://doi.org/10.1016/j.nanoms.2019.02.004.

[11] H. Fukushima, L. T. Drzal, B. P. Rook, and M. J. Rich, "Thermalconductivity of exfoliated graphite nanocomposites," J. Therm. Anal. Calorim., vol. 85, no. 1, pp. 235-238, 2006, doi: 10.1007/s10973-005-7344-x.

[12] A. Kumar, K. Sharma, and A. Dixit, "A review on the mechanical properties of polymer composites reinforced by carbon nanotubes and graphene," Carbon Lett., vol. 31, Jun. 2020, doi: 10.1007/s42823-020-00161-x.

[13] J. Moser, A. Barreiro, and A. Bachtold, "Current-induced cleaning of graphene," Appl. Phys. Lett., vol. 91, p. 163513, Nov. 2007, doi: 10.1063/1.2789673.

[14] A. Kumar, K. Sharma, and A. Dixit, "Carbon nanotube- and graphene-reinforced multiphase polymeric composites: review on their properties and applications," $J$. Mater. Sci., vol. 55, Mar. 2020, doi: 10.1007/s10853-019-04196-y.

[15] S. Yu, S. Yang, and M. Cho, "Multi-scale modeling of cross-linked epoxy 
nanocomposites," Polymer (Guildf)., 2009, doi: 10.1016/j.polymer.2008.11.054.

[16] H. B. Fan and M. M. F. Yuen, "Material properties of the cross-linked epoxy resin compound predicted by molecular dynamics simulation," Polymer (Guildf)., 2007, doi: 10.1016/j.polymer.2007.02.007.

[17] N. Nouri and S. Ziaei-Rad, "A Molecular Dynamics Investigation on Mechanical Properties of Cross-Linked Polymer Networks," Macromolecules, vol. 44, no. 13, pp. 5481-5489, Jul. 2011, doi: 10.1021/ma2005519.

[18] C. Li and A. Strachan, "Molecular simulations of crosslinking process of thermosetting polymers," Polymer (Guildf)., vol. 51, no. 25, pp. 6058-6070, 2010, doi: https://doi.org/10.1016/j.polymer.2010.10.033.

[19] V. Varshney, S. Patnaik, A. Roy, and B. Farmer, “A Molecular Dynamics Study of Epoxy-Based Networks: Cross-Linking Procedure and Prediction of Molecular and Material Properties," Macromolecules, vol. 41, Aug. 2008, doi: 10.1021/ma801153e.

[20] J. L. Tack and D. M. Ford, "Thermodynamic and mechanical properties of epoxy resin DGEBF crosslinked with DETDA by molecular dynamics," J. Mol. Graph. Model., vol. 26, no. 8, pp. 1269-1275, 2008, doi: https://doi.org/10.1016/j.jmgm.2007.12.001.

[21] H. Hörstermann, R. Hentschke, M. Amkreutz, M. Hoffmann, and M. WirtsRütters, "Predicting Water Sorption and Volume Swelling in Dense Polymer Systems via Computer Simulation," J. Phys. Chem. B, vol. 114, no. 51, pp. 1701317024, Dec. 2010, doi: 10.1021/jp105210y.

[22] C. Wu and W. Xu, "Atomistic simulation study of absorbed water influence on structure and properties of crosslinked epoxy resin," Polymer (Guildf)., vol. 48, no. 18, pp. 5440-5448, 2007, doi: https://doi.org/10.1016/j.polymer.2007.06.038.

[23] S. P. A V S, G. Tarun, and S. Basu, "Coarse - grained molecular dynamics simulation of cross - linking of DGEBA epoxy resin and estimation of the adhesive strength," Int. J. Eng. Sci. Technol., vol. 2, Sep. 2010, doi: 10.4314/ijest.v2i4.59196.

[24] H. Liu, M. Li, Z.-Y. Lu, Z.-G. Zhang, C.-C. Sun, and T. Cui, "Multiscale Simulation Study on the Curing Reaction and the Network Structure in a Typical 
Epoxy System," Macromolecules, vol. 44, Oct. 2011, doi: 10.1021/ma201390k.

[25] T. C. Clancy, S. J. V Frankland, J. A. Hinkley, and T. S. Gates, "Molecular modeling for calculation of mechanical properties of epoxies with moisture ingress," Polymer (Guildf)., vol. 50, no. 12, pp. 2736-2742, 2009, doi: https://doi.org/10.1016/j.polymer.2009.04.021.

[26] N. Soni, P.-H. Lin, and R. Khare, "Effect of cross-linker length on the thermal and volumetric properties of cross-linked epoxy networks: A molecular simulation study," Polymer (Guildf)., vol. 53, pp. 1015-1019, Feb. 2012, doi: 10.1016/j.polymer.2011.12.051.

[27] S.-H. Chang and H.-S. Kim, "Investigation of hygroscopic properties in electronic packages using molecular dynamics simulation," Polymer (Guildf)., vol. 52, no. 15, pp. 3437-3442, 2011, doi: https://doi.org/10.1016/j.polymer.2011.05.056.

[28] M. Tsige and M. J. Stevens, "Effect of Cross-Linker Functionality on the Adhesion of Highly Cross-Linked Polymer Networks: A Molecular Dynamics Study of Epoxies," Macromolecules, vol. 37, no. 2, pp. 630-637, Jan. 2004, doi: 10.1021/ma034970t.

[29] O. Hölck, E. Dermitzaki, B. Wunderle, J. Bauer, and B. Michel, "Basic thermomechanical property estimation of a 3D-crosslinked epoxy/SiO2 interface using molecular modelling," Microelectron. Reliab., vol. 51, no. 6, pp. 1027-1034, 2011, doi: https://doi.org/10.1016/j.microrel.2011.03.014.

[30] M. Ionita, "Multiscale molecular modeling of SWCNTs/epoxy resin composites mechanical behaviour," Compos. Part B Eng., vol. 43, no. 8, pp. 3491-3496, 2012, doi: https://doi.org/10.1016/j.compositesb.2011.12.008.

[31] R. Zhu, E. Pan, and A. K. Roy, "Molecular dynamics study of the stress-strain behavior of carbon-nanotube reinforced Epon 862 composites," Mater. Sci. Eng. A, 2007, doi: 10.1016/j.msea.2006.10.054.

[32] Y. Li, M. Kröger, and W. K. Liu, "Primitive chain network study on uncrosslinked and crosslinked cis-polyisoprene polymers," Polymer (Guildf)., vol. 52, no. 25, pp. 5867-5878, 2011, doi: https://doi.org/10.1016/j.polymer.2011.10.044.

[33] B. Wunderle et al., "Molecular dynamics approach to structure-property correlation in epoxy resins for thermo-mechanical lifetime modeling," 
Microelectron. Reliab., vol. 50, no. 7, pp. 900-909, 2010, doi: https://doi.org/10.1016/j.microrel.2010.02.024.

[34] I. Yarovsky and E. Evans, "Computer simulation of structure and properties of crosslinked polymers: application to epoxy resins," Polymer (Guildf)., vol. 43, no. 3, pp. 963-969, 2002, doi: https://doi.org/10.1016/S0032-3861(01)00634-6.

[35] B. Qi and J. Yu, "Enhanced thermal and mechanical properties of epoxy composites by mixing thermotropic liquid crystalline epoxy grafted graphene oxide," Express Polym. Lett., vol. 8, pp. 467-479, Apr. 2014, doi: 10.3144/expresspolymlett.2014.51.

[36] P. Nayebi and E. Zaminpayma, "A molecular dynamic simulation study of mechanical properties of graphene-polythiophene composite with Reax force field," Phys. Lett. A, vol. 380, no. 4, pp. 628-633, 2016, doi: https://doi.org/10.1016/j.physleta.2015.11.026.

[37] M.-W. Lee, T.-Y. Wang, and J.-L. Tsai, "Mechanical properties of nanocomposites with functionalized graphene," J. Compos. Mater., vol. 50, no. 27, pp. 3779-3789, Jan. 2016, doi: 10.1177/0021998315625788.

[38] F. Lin, Y. Xiang, and H.-S. Shen, “Temperature dependent mechanical properties of graphene reinforced polymer nanocomposites - A molecular dynamics simulation," Compos. Part B Eng., vol. 111, pp. 261-269, 2017, doi: https://doi.org/10.1016/j.compositesb.2016.12.004.

[39] H. Yu, Z. Tong, P. Chen, A. Cai, and F. Qin, "Effects of different parameters on thermal and mechanical properties of aminated graphene/epoxy nanocomposites connected by covalent: A molecular dynamics study," Curr. Appl. Phys., vol. 20, pp. 510-518, 2020.

[40] M. K. Shukla, A. Kumar, A. Yadav, and K. Sharma, "Improved mechanical properties of graphene oxide reinforced cross-linked epoxy nanocomposites: A molecular dynamics approach,” 2019, doi: 10.1016/j.matpr.2019.03.027.

[41] K. Sharma, K. Sen Kaushalyayan, and M. Shukla, "Pull-out simulations of interfacial properties of amine functionalized multi-walled carbon nanotube epoxy composites," Comput. Mater. Sci., vol. 99, pp. 232-241, 2015, doi: https://doi.org/10.1016/j.commatsci.2014.12.023. 
[42] K. Sharma and D. M. Shukla, "Molecular modeling of the mechanical behavior of carbon fiber-amine functionalized multiwall carbon nanotube/epoxy composites," New Carbon Mater., vol. 29, pp. 132-142, Apr. 2014, doi: 10.1016/S18725805(14)60131-1.

[43] A. Shokuhfar and B. Arab, "The effect of cross linking density on the mechanical properties and structure of the epoxy polymers: Molecular dynamics simulation," J. Mol. Model., vol. 19, Jun. 2013, doi: 10.1007/s00894-013-1906-9.

[44] F. Jeyranpour, G. Alahyarizadeh, and B. Arab, "Comparative investigation of thermal and mechanical properties of cross-linked epoxy polymers with different curing agents by molecular dynamics simulation," J. Mol. Graph. Model., 2015, doi: 10.1016/j.jmgm.2015.09.012.

[45] H. Sun, "COMPASS: An ab Initio Force-Field Optimized for Condensed-Phase ApplicationsOverview with Details on Alkane and Benzene Compounds," J. Phys. Chem. B, vol. 102, no. 38, pp. 7338-7364, Sep. 1998, doi: 10.1021/jp980939v.

[46] Z. Zhou and B. Joó, "Fluctuation formulas for the elastic constants of an arbitrary system," Phys. Rev. B - PHYS REV B, vol. 66, Aug. 2002, doi: 10.1103/PhysRevB.66.054101.

[47] Y. Han and J. Elliott, "Molecular dynamics simulations of the elastic properties of polymer/carbon nanotube composites," Comput. Mater. Sci., vol. 39, no. 2, pp. 315-323, 2007, doi: https://doi.org/10.1016/j.commatsci.2006.06.011.

[48] D. N. Theodorou and U. W. Suter, "Atomistic modeling of mechanical properties of polymeric glasses," Macromolecules, vol. 19, no. 1, pp. 139-154, Jan. 1986, doi: 10.1021/ma00155a022.

[49] R. Sun, L. Li, C. Feng, S. Kitipornchai, and J. Yang, "Tensile behavior of polymer nanocomposite reinforced with graphene containing defects," Eur. Polym. J., vol. 98, pp. 475-482, 2018, doi: https://doi.org/10.1016/j.eurpolymj.2017.11.050.

[50] M. A. Rafiee et al., "Graphene Nanoribbon Composites," ACS Nano, vol. 4, no. 12, pp. 7415-7420, Dec. 2010, doi: 10.1021/nn102529n.

[51] E. N. Skountzos, A. Anastassiou, V. G. Mavrantzas, and D. N. Theodorou, "Determination of the Mechanical Properties of a Poly(methyl methacrylate) Nanocomposite with Functionalized Graphene Sheets through Detailed Atomistic 
Simulations," Macromolecules, vol. 47, no. 22, pp. 8072-8088, Nov. 2014, doi: 10.1021/ma5017693.

[52] S. K. Yadav and J. W. Cho, "Functionalized graphene nanoplatelets for enhanced mechanical and thermal properties of polyurethane nanocomposites," Appl. Surf. Sci., 2013, doi: 10.1016/j.apsusc.2012.12.028.

[53] F. Wang, L. Drzal, Y. Qin, and Z. Huang, "Size effect of graphene nanoplatelets on the morphology and mechanical behavior of glass fiber/epoxy composites," $J$. Mater. Sci., vol. 51, pp. 1-12, Apr. 2016, doi: 10.1007/s10853-015-9649-x.

[54] S. C. Zunjarrao and R. P. Singh, "Characterization of the fracture behavior of epoxy reinforced with nanometer and micrometer sized aluminum particles," Compos. Sci. Technol., 2006, doi: 10.1016/j.compscitech.2005.12.001.

[55] Y.-J. Wan, L.-X. Gong, L.-C. Tang, L.-B. Wu, and J.-X. Jiang, "Mechanical properties of epoxy composites filled with silane-functionalized graphene oxide," Compos. Part A Appl. Sci. Manuf., vol. 64, pp. 79-89, 2014, doi: https://doi.org/10.1016/j.compositesa.2014.04.023.

[56] S. HER and L. CHEN, "Fabrication and Characterization of Graphene/Epoxy Nanocomposites," Mater. Sci., vol. 25, pp. 433-440, Jun. 2019, doi: 10.5755/j01.ms.25.4.19462.

[57] K.-Y. Li et al., "Preparation and properties of novel epoxy/graphene oxide nanosheets (GON) composites functionalized with flame retardant containing phosphorus and silicon," Mater. Chem. Phys., vol. 146, pp. 354-362, Aug. 2014, doi: 10.1016/j.matchemphys.2014.03.037.

[58] S. Yang, H. Shin, and M. Cho, "Contribution of oxygen functional groups in graphene to the mechanical and interfacial behaviour of nanocomposites: Molecular dynamics and micromechanics study," Int. J. Mech. Sci., 2021, doi: 10.1016/j.ijmecsci.2020.105972.

[59] H. Yao, S. A. Hawkins, and H.-J. Sue, "Preparation of epoxy nanocomposites containing well-dispersed graphene nanosheets," Compos. Sci. Technol., vol. 146, pp. 161-168, 2017, doi: https://doi.org/10.1016/j.compscitech.2017.04.026.

[60] D. Galpaya, M. Wang, G. George, N. Motta, E. Waclawik, and C. Yan, "Preparation of graphene oxide/epoxy nanocomposites with significantly improved 
mechanical properties," J. Appl. Phys., vol. 116, p. 53518, Aug. 2014, doi: 10.1063/1.4892089.

[61] Y. Qian, Y. Lan, J. Xu, F. Ye, and S. Dai, "Fabrication of polyimide-based nanocomposites containing functionalized graphene oxide nanosheets by in-situ polymerization and their properties," Appl. Surf. Sci., vol. 314, pp. 991-999, 2014, doi: https://doi.org/10.1016/j.apsusc.2014.06.130.

[62] T.-Y. Wang, P.-Y. Tseng, and J.-L. Tsai, "Characterization of Young's modulus and thermal conductivity of graphene/epoxy nanocomposites," J. Compos. Mater., vol. 53, no. 6, pp. 835-847, Jul. 2018, doi: 10.1177/0021998318791681.

[63] J. R. Potts et al., "Thermomechanical properties of chemically modified graphene/poly(methyl methacrylate) composites made by in situ polymerization," Carbon N. Y., vol. 49, no. 8, pp. 2615-2623, 2011, doi: https://doi.org/10.1016/j.carbon.2011.02.023.

[64] A. Yadav, A. Kumar, K. Sharma, and M. Shukla, "Investigating the Effects of Amine Functionalized Graphene on the Mechanical Properties of Epoxy Nanocomposites," Mater. today Proc., vol. 11, pp. 837-842, Mar. 2019, doi: 10.1016/j.matpr.2019.03.054.

[65] M. Rafiee, J. Rafiee, Z. Wang, H.-H. Song, Z.-Z. Yu, and N. Koratkar, "Enhanced Mechanical Properties of Nanocomposites at Low Graphene Content," ACS Nano, vol. 3, pp. 3884-3890, Dec. 2009, doi: 10.1021/nn9010472. 